\title{
Automated gas bubble imaging at sea floor - a new method of in situ gas flux quantification
}

\author{
K. Thomanek ${ }^{1}$, O. Zielinski ${ }^{1,3}$, H. Sahling ${ }^{2}$, and G. Bohrmann ${ }^{2}$ \\ ${ }^{1}$ University of Applied Sciences Bremerhaven, An der Karlstadt 8, 27568 Bremerhaven, Germany \\ ${ }^{2}$ MARUM Center for Marine Environmental Sciences, University of Bremen, Klagenfurter Str., 28359 Bremen, Germany \\ ${ }^{3}$ IMARE Institute for Marine Resources, Bussestr. 27, 27570 Bremerhaven, Germany
}

Received: 29 December 2009 - Published in Ocean Sci. Discuss.: 9 February 2010

Revised: 27 May 2010 - Accepted: 28 May 2010 - Published: 7 June 2010

\begin{abstract}
Photo-optical systems are common in marine sciences and have been extensively used in coastal and deepsea research. However, due to technical limitations in the past photo images had to be processed manually or semiautomatically. Recent advances in technology have rapidly improved image recording, storage and processing capabilities which are used in a new concept of automated in situ gas quantification by photo-optical detection. The design for an in situ high-speed image acquisition and automated data processing system is reported ("Bubblemeter"). New strategies have been followed with regards to back-light illumination, bubble extraction, automated image processing and data management. This paper presents the design of the novel method, its validation procedures and calibration experiments. The system will be positioned and recovered from the sea floor using a remotely operated vehicle (ROV). It is able to measure bubble flux rates up to $10 \mathrm{~L} / \mathrm{min}$ with a maximum error of $33 \%$ for worst case conditions. The Bubblemeter has been successfully deployed at a water depth of $1023 \mathrm{~m}$ at the Makran accretionary prism offshore Pakistan during a research expedition with R/V Meteor in November 2007.
\end{abstract}

\section{Introduction}

The observation of bubbles in fluids is of primary importance for many physical, medical and chemical engineering processes. In deep-sea research, methane gas seeps have been found to be vital sources of energy for seep communities

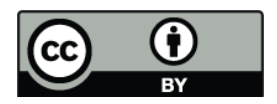

Correspondence to: O. Zielinski (ozielinski@hs-bremerhaven.de)
(Boetius et al., 2000; Orphan et al., 2001). Medical examinations of bubbles in blood vessels have been motivated by decompression studies (MacKay and Rubisson, 1978; Belcher, 1980). Other industrial processes, such as waste water treatment for example, require dispersion of a gas into a liquid medium (Michelson et al., 1988; Reible, 1999). The dispersion rate of gas bubbles into a liquid media is, among others, controlled by the bubble interfacial area. The dispersion efficiency, however, is controlled by the ratio of surface area to bubble volume (Deckwer, 1985). Therefore, determining the bubble size distribution is a key element for any of the disciplines above.

Methane is a potent atmospheric greenhouse gas, which is naturally released from the seafloor at many sites along continental margins. Although numerous gas seeps have been discovered world wide, little is known about local gas fluxes and their temporal and spatial variation (Judd, 2004). Furthermore, the fate of methane after being released from the seafloor is often unknown. While methane bubbles, escaping from shallow seeps such as the Coal Oil Point offshore Santa Barbara (Hornafius et al., 1999) enter the atmosphere, there is evidence that methane from deep-sea sources at water depths of about $2000 \mathrm{~m}$ is completely dispersed and oxidized in the water column before it reaches surface waters (McGinnis et al., 2006).

There are only a few locations in the world where the bubble flux has been quantified by order-of-magnitude estimations at deep-sea depths, these are Håkon Mosby mud volcano (1250 m) (Sauter et al., 2006), at Hydrate Ridge (580 to $780 \mathrm{~m}$ ) (Torres et al., 2002), in the Gulf of Mexico (525 to $550 \mathrm{~m}$ ) (Leifer and MacDonald, 2003), and at Vodyanitskii Mud Volcano (2070 m) (Sahling et al., 2009). At those locations, single seep vents were observed with in situ flux rates ranging between approximately 0.1 and $5 \mathrm{~L} / \mathrm{min}$.

Published by Copernicus Publications on behalf of the European Geosciences Union. 
Methane ebullition occurring at Håkon Mosby mud volcano or the southern summit of Hydrate Ridge is affected by hydrate formation. Both sites are well within the hydrate stability field causing rapid hydrate coating of the gas bubbles that are released from the sea floor (Sauter et al., 2006; Suess et al., 2001).

The study by McGinnis et al. (2006) employs a bubble model in order to estimate the fate of methane and other gases while a bubble rises through the water column at different depths. The model also accounts for reduced gas exchange due to the formation of a hydrate skin around the bubble. The key parameters that control the fate of a bubble are release depth, bubble size, dissolved gas concentration, temperature, surface-active substances and bulk fluid motions (Leifer and Patro, 2002). While small bubbles survive a short distance only, larger bubbles carry the majority of the released methane into much shallower depth.

So far, the model by McGinnis et al. (2006) has only been applied to a gas bubble stream that is emitted from a mud volcano in the Black Sea due to the lack of adequate data from other natural gas seeps. Thus, quantifying methane gas flux at individual outlets along with its bubble size distribution and rise velocity is a first key step for estimating the impact of methane on the hydrosphere and eventually on the atmosphere.

A variety of optical as well as acoustical methods have been developed to address the issue of bubble analysis. In acoustics, bubble size information can be obtained either from active or passive techniques. The latter uses sound emitted by excited bubbles during the detachment process (Nikolovska et al., 2007). Very shortly after detachment, the passive signal ceases and further detection must be utilizing an acoustically active method. This may include or combine any of the techniques described below which are summarized, for example, in Leighton et. al. (1998). There is ultrasound scattering using continuous wave insonification and pulse echo methods that use the transit time of pulse signals to calculate bubble positions. Acoustic resonators size bubbles by using frequencies which excite bubbles at their resonance. Applied to marine science, acoustic methods have been valuable for investigating a variety of research fields reaching from marine fish ecology studies to geo-marine subsea and sub-bottom profiling. With respect to bubbles in the ocean acoustic methods have been extensively deployed, investigating bubble creation mechanism in breaking waves (Lamarre and Melville, 1992; Deane and Stokes, 2002).

However, little acoustic data is available in quantifying methane seeps in the deep sea. Greinert and Nützel have developed a horizontally looking single beam transducer. They demonstrated that the gas flux is proportional to the backscatter of the insonified volume at flow rates up to $20 \mathrm{~L} / \mathrm{min}$ (Greinert and Nützel, 2004). Nikolovska and Waldmann presented a study quantifying underwater gas seepage using passive acoustics (Nikolovska and Waldmann, 2006). Nikolovska and co-authors also employed a horizontally looking sonar mounted onto a ROV in order to quantify gas emission offshore Georgia at the eastern part of the Black Sea (Nikolovska et al., 2008). For gas quantification and bubble analysis, acoustic methods have the clear advantage of covering large fields of observation and not interfering hydrodynamically with the volume of observation. Yet, to our knowledge, there is only one system developed for deep-sea applications capable of obtaining bubble size information using a horizontally looking swath system. The GasQaunt system was developed by Greinert and Nützel in cooperation with ELAC Nautik in Kiel, Germany (Greinert and Nützel, 2004).

There is a vast range of optical instruments in marine science. These include laser scattering (Agrawal and Pottsmith, 1989), diffraction (de Vries et al., 2002; Karpen et al., 2004) and optical imaging (Eisma et al., 1990). For deep-sea applications, optical imaging systems have become an important tool. Cameras, mounted on remotely operated vehicles or deployed as autonomous devices, have given an intuitive insight into the deep-sea environment. Moreover, camera and video pictures may be analysed quantitatively with respect to size, shape, colour and velocity (Zielinski et al., 2010).

Although it is of high interest quantifying the amount of methane escaping seepage systems, there are only a few systems available which are capable of providing data about local bubble size distributions and gas flux. Leifer and Boles designed a diver operated bubble measurement device which is able to visually record and analyse bubble streams for shallow water applications up to $30 \mathrm{~m}$ (Leifer and Boles, 2005). The system uses backlight illumination where the objects are located in between the light source and the camera. It can measure flow rates and bubble size distributions simultaneously.

Leifer and MacDonald also employed a manned submersible to record image data on bubble seeps in the Gulf of Mexico. These images were processed manually. The local gas flux was estimated to be $62.3 \times 10^{-3}$ mol per second, equivalent to $1.5 \mathrm{~L} / \mathrm{min}$ (Leifer and MacDonald, 2003). At Håkon Mosby mud volcano the bubbles were recorded using ROV cameras. During post-processing, single frames were analysed and the total gas volume determined. The gas flux was quantified to be $200 \times 10^{-3} \mathrm{~mol}$ per second, equivalent to $1.6 \mathrm{~L} / \mathrm{min}$ under in situ conditions (Sauter et al., 2006). Sahling et al. (2009) quantified gas fluxes in the range of 0.03 to $0.12 \mathrm{~L} / \mathrm{min}$ for the Vodyanitskii mud volcano in the Black Sea based on ROV videos. At Hydrate Ridge, gas quantification was performed using a funnel technique. An in situ flow rate of $5 \mathrm{~L} / \mathrm{min}$ was estimated by determining the time required to displace the fluid inside the gas collector (Torres et al., 2002).

The work presented in this study is a result of the limited availability of deep-sea deployable systems for gas quantification and bubble analysis. Potential seep measurements are planned at locations situated within the hydrate stability field where the flux is expected to be in the order of $0.1-10 \mathrm{~L} / \mathrm{min}$. 
Due to increased spatial bubble density at $2 \mathrm{~L} / \mathrm{min}$ and above bubble flow characteristics are heavily dominated by bubble overlap when using a 2-D projection of the field of observation. This work describes and evaluates methods to empirically estimate the proposed error due to bubble overlap. Natural changes in gas flux as well as tide-related fluctuations shall be examined in future. Therefore, a new optical system was developed that automatically determines the size and velocity of bubbles as well as the gas flux. The key objective for this new design is to be able to monitor bubble seeps for an extended period of time.

This can be achieved, for example, by optically imaging gas bubbles while they rise through the volume of observation. Discriminating bubbles successfully and efficiently from their background is of utmost importance for further data analysis. Object segmentation and analysis is also a common problem in many other engineering, medical and marine science disciplines. The primary intention is always to increase sample density to decrease random errors made by human misjudgement and to make data analysis faster and easier. With routines capable of systematically analysing an arbitrary amount of image sequences, long-term monitoring may be feasible in future. Without requiring high human resources, comparisons of bubble flux correlated to environmentally changing parameters can be investigated then.

Focusing on micro-bubbles, Stokes and Deane introduced an optical instrument for the study of bubbles within breaking waves (Stokes and Deane, 1999). One key element in their automatic image processing strategy is an elaborate technique to reduce effects in variations of background illumination intensities. Their second key innovation in processing bubble images is the application of a HoughTransform (HT). The principle of HT is to transform the real space coordinates $(x, y)$ of bubble edges to the Hough space with perimeter $(a, b)$ and radius $(r)$ as parameters. Local peaks in a frequency distribution of $(a, b, r)$ indicate centres of bubbles with radius $r$. This is a robust technique for analysing circular shaped objects. However, the comparatively long processing time is one reason why this segmentation strategy had not been considered here. Yet, recent works on bubbles in bioreactors have increased processing speed using HT and show that this method is clearly superior to manual analysis (Taboada et al., 2006).

Another bubble measurement system originally developed for breaking waves was developed by Leifer et al. (2003). This system discriminates bubbles from their background by means of a preset grey value threshold. This method rapidly produces binary images of bubbles since no time consuming filters are required. However, the true bubble size may be corrupted due to off-axis illumination, which results in an external bright ring that obscures the true bubble edge. Consequently, a different segmentation strategy is needed to identify bubbles efficiently within the specified accuracy. The image processing routine will be discussed in detail within this paper.

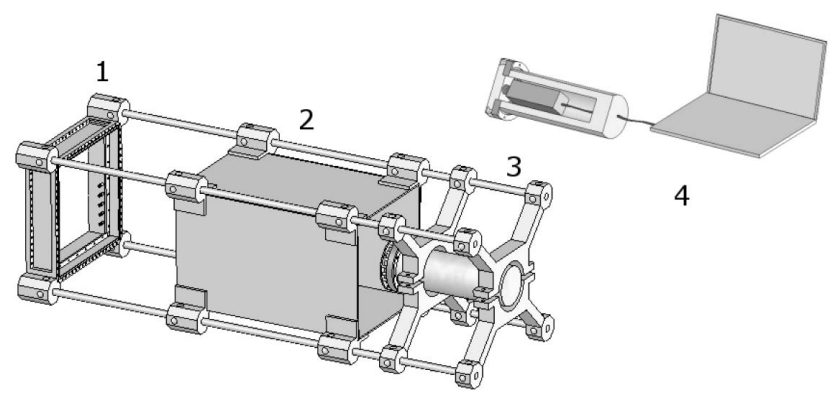

Fig. 1. Schematic illustration of the Bubblemeter: A homogeneous high intensity light source combined with a power pack (Device 1) illuminates the field of observation. A box (Device 2) filled with clear water reduces water turbidity within the optical path. A high speed camera inside a pressure housing (Device 3 ) records sequences of bubble images which rise in the sample area between Device (1) and (2). Data sequences are transferred to a laptop PC (4) for further analysis.

In summary, the camera system, hereafter referred to as "Bubblemeter", is designed to be deployed and recovered from the deep sea using a remotely operated vehicle. It consists of a state-of-the-art high-speed camera providing high time and spatial resolution. The required intensive illumination is achieved by an innovative LED light source. The postprocessing procedures and bubble analysis is accomplished by an automated routine capable of identifying bubbles and measuring key features like vertical bubble speed and bubble dimensions. These parameters are essential in determining the liquid-gas mass exchange at the fluid interface. Moreover, images with very high time resolution of methane bubbles may give new insights to possible hydrate skin formation. The Bubblemeter development is a three stage process. It is split into a validation and surface supplied deep-sea testing phase. The third stage consists of a system modification towards an autonomous operation. Here, we report on the first two stages of development.

\section{Materials and Procedures}

\subsection{Bubblemeter design and components}

The camera system consists of four components as illustrated in Fig. 1: The illumination and power storage unit (Device 1), water box (Device 2), high-speed camera (Device 3) and the data storage unit (4). The total mass of $60 \mathrm{~kg}$ exhibits a negative buoyancy of $200 \mathrm{~N}$ in fresh water. The overall dimensions are $140 \mathrm{~cm} \times 50 \mathrm{~cm} \times 50 \mathrm{~cm}$.

The bubble quantification system was designed in a modular fashion to assist various stages of development. For the verification process, the modules light and power source are combined with a high-speed camera mounted onto the pressure housing. The camera is connected to a laptop PC and allows real-time observation of bubble streams. This 
laboratory version for shallow water applications can be deployed to a water depth of $2 \mathrm{~m}$, restricted only by the cable length between camera and laptop. Longer cables may be used but require additional shielding due to changes in the self-inductivity while submerged. The deep-sea nonautonomous version of the Bubblemeter consists of the same components as the laboratory version with only two differences. The camera running on an autonomous mode can be triggered only once per dive. Secondly, the switch must be triggered by a ROV manipulator externally. In the final stage of development, the major difference to previous versions will be the control and data storage unit which will be additionally incorporated into the pressure housing. This unit will allow triggering of camera and illumination in preset frequencies and storing recorded images. In order to preserve energy, the control unit will set the system to standby while it is not in record mode.

Illumination: Arguably, the light source is the heart of every image processing tool. Gradients in background intensity require complex filters and computing time in order to extract bubble objects from their surrounding. A homogenously illuminated field-of-view simplifies any segmentation strategy. Fast moving objects like bubbles require high shutter speeds and a small camera aperture. Therefore, high light intensities are mandatory in order to minimize motion blur to less than 2 pixels. Also small size, low weight and low power uptake are general requirements for ROV-operated as well as autonomous underwater tools. As a result, a novel high intensity light source made out of LEDs was developed to meet all requirements above.

The novel light source developed for the Bubblemeter employs LEDs that densely cover a square area of $30 \mathrm{~cm} \times 30 \mathrm{~cm}$ and act as point sources of light. The wavelength is Gaussian distributed with its peak at $\mu=524 \mathrm{~nm}$ and a deviation of $\sigma=10 \mathrm{~nm}$. A $3 \mathrm{~mm}$ thick screen made out of polyethylene diffuses the led spots and creates a homogeneous background. In air, the field of observation can be illuminated with a homogeneous light intensity of 60 Klux. The power consumption is $170 \mathrm{~W}$ at 12 VDC which is supplied by a $10 \mathrm{Ah}$ built-in Lithium-Polymer rechargeable battery pack. In this configuration, the energy capacity is sufficient in illuminating the field of observation approximately 60 times under laboratory conditions. Each interval lasts $10 \mathrm{~s}$. Due to the fact that the required voltage for the LED configuration can only be provided for a fraction of the total battery capacity, this large margin was chosen, also taking into account varying discharge characteristics for low temperatures occurring at deep-sea sites. The illumination housing is designed to accommodate a 40 Ah battery pack of the same make. Potentially, this increases the number of activations to approximately 240 . The housing is pressure compensated and filled with silicone oil. This enables quick transport of heat energy to the surfaces, as well as a thin walled and lightweight housing.

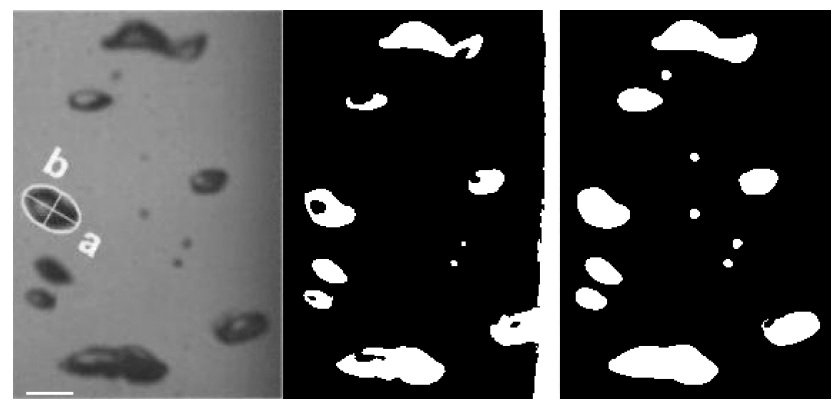

Fig. 2. Left; Inhomogeneously illuminated grey scale image. Parameter " $a$ " and " $b$ " denote the major and minor axis of a best fit ellipse encircling the bubble. The white scale bar has a length of $10 \mathrm{~mm}$. Centre; Bubble segmentation using the threshold method. Right; Bubble segmentation applying the edge detection method. The edge detection method results in an accurate representation of the bubbles and is, in addition, less sensitive to inhomogeneous background illumination compared to the threshold method.

Frame: The frame consists of 4 stainless steel bars and act as a guide rail. It accommodates the pressure container, the clear vision box and the illumination device. The size was chosen considering the technical feasibility in a remote operated vehicle deployment as well as ensuring that even fast moving bubbles can be tracked for a sufficiently long time. Due to the adjustable design, the length of the system may be varied as appropriate. For turbid waters, a clear vision box may be used. This box, filled either with clear saline or non-saline water, reduces the volume of potentially turbid water in front of the screen, thus, enhancing the image contrast. Normally the clear vision box would be filled with surface water on site. Alternatively, the box may be filled with transparent oil in order to increase buoyancy.

Camera and optics: A Weinberger high-speed camera using CMOS sensors and fire wire IEEE1394 interface technology is used to record 1000 frames per sequence. It requires $25 \mathrm{~W}$ at $12 \mathrm{VDC}$ which can be supplied either by an external power source or an internal rechargeable battery pack. The spatial resolution is $1280 \times 1024$ pixels (px) while the time resolution can be varied between $62,250,500$ to maximum 32000 frames per second (fps) at reduced spatial resolution. An electronic shutter speed of $250 \mu$ s results in sufficient high contrast while motion blur is minimized to within specified levels. Initially the images are stored within the camera and must then be transferred onto a control unit for further processing. A Pentax $25 \mathrm{~mm}$ TV lens with adjustable focus was used at an aperture setting of $f / 8$. This setting enables the depth of focus to cover the complete volume of observation.

Computer hardware and supplemental software: A conventional laptop PC with a $1.73 \mathrm{GHz}$ Intel ${ }^{\circledR}$ Pentium ${ }^{\circledR} \mathrm{M}$ and IEEE1394 interface is used to control the camera settings and to conduct the data upload, applying "Motionfire" by Weinberger Vision. All image processing and analysis is performed using Matlab® code and its libraries. 


\subsection{Image processing and analysis}

An automated routine is needed in order to process and analyse images with statistically relevant numbers of gas bubbles within reasonable time and accuracy. The algorithm must perform simple and fast segmentation as well as feature extraction. Furthermore, the algorithm must be capable of tracking individual bubbles and store the results in a useful format. Therefore, the key features of the presented routine may be summarized by isolating bubbles from the background and determining their position and bubble sizes. In a second step, the routine can track bubbles in successive frames, analyse and store the data in a cubic matrix. The following paragraph describes the new concept in detail.

In general, segmentation is the process of discriminating objects of interest from the remaining image. In this case, it is the process deciding whether any image pixel belongs to a bubble or is part of the background. In the segmentation strategy followed in this study, a "Canny" filter is used for grey value images. It compares the value of each pixel relative to the values of its neighbourhood (Canny, 1986). When the grey value gradient between two adjacent pixels is larger than a preset level, the pixel is set to binary 1 , otherwise it is set to binary 0 . As a result, edges are created around objects.

The major advantage of using the edge detection strategy rather than applying a simple grey value threshold is illustrated in Fig. 2. The edge detection identifies the bubble boundaries even in inhomogenously illuminated areas. Furthermore, it can also be applied to images with steadily decreasing light intensities. In contrast, the image that is segmented using a grey value threshold shows some degeneration in bubble shape. Also the background may be misinterpreted due to the inhomogeneous background illumination.

However, there are two disadvantages in using the edge detection strategy, which we consider as minor compared to the improvement of the method. One disadvantage is the increased computing time compared to using the intensity threshold. The computing time varies between milliseconds and seconds and depends on the image size. The second disadvantage is a systematic enhancing or suppressing of bubble boundaries. Depending on the edge threshold the bubble grows or shrinks during segmentation. This can be compensated using dilation and erosion filters which add or subtract pixels to the boundaries of objects. Yet, applying additional morphological filters requires extra processing time and adds on to the first disadvantage. The final output is a binary image which is an isometric mapping of the original image.

In general, feature extraction is the process of reducing the object information to the relevant key features of interest. Here, the bubble size as well as the centre of the bubble area is determined using the Matlab ${ }^{\circledR}$ routine "Regionprops". These values are based on an elliptical best fit as exemplified in Fig. 2.

In a second step, bubbles are tracked in successive frames and their rise velocities are computed. This is realized using the following assumption: the distance that a bubble has travelled in two successive images is smaller than the distance to its closest neighbour. This assumption is valid except for overlapping bubbles, very high bubble concentration and for low acquisition frequencies where travel distance is greater than neighboured bubble distance. Objects that do not move or sink are automatically excluded.

Finally, the vertical flux of bubbles through the sample volume is calculated. Since bubbles are imaged and measured multiple times during their rise, each measurement has to be weighted by a weighting factor $\eta$. It represents the number of measurements made of a single bubble during its rise through the sample volume and is determined by the following equation:

$\eta=\frac{(Y-2 \cdot h)}{D_{z}}$

where $D_{z}$ is the vertical shift of an individual bubble. $Y$ represents the image size in vertical direction and $h$ the vertical bubble diameter. For example, in order to count bubbles, each measurement results in an increase of the bubble number by $\frac{1}{\eta}$. After $\eta$ measurements of the same bubble, its bubble number has risen to $\frac{\eta}{\eta}=1$ while the bubble has left the image. Therefore, intermittent errors such as bubble overlap or unsuccessful bubble assignment contribute by a factor $\frac{1}{\eta}$ to each measurement only. At the same time, the reciprocal factor may also be interpreted as particle flux through the horizontal cross-section. Thus, the higher the image acquisition frequency and the lower the rise velocity to the limit where motion can no longer be detected, the larger $\eta$ is, the smaller is the contributing error. This weighting factor also applies to variations in bubble numbers and rise speed.

\section{Assessment}

Three key experiments were conducted to test the concept of the gas quantification system. Firstly, the reliability of the automated segmentation routine and bubbles size measurement was tested. The results showed that the system maps bubble images onto binary images isometrically. Secondly, parameters for assessing the bubble assignment ability were introduced. It shows that at least $75 \%$ of the bubbles are assigned correctly. Thirdly, a series of calibrated gas flux measurements between $2 \mathrm{~L} / \mathrm{min}$ and $12 \mathrm{~L} / \mathrm{min}$ were performed. The results reveal a linear dependence between the flux determined by the Bubblemeter and the actual gas flux. The system is able to determine gas flow rates in the order of magnitudes of $\mathrm{mL} / \mathrm{min}$ up to an amount of $10 \mathrm{~L} / \mathrm{min}$. The error is typically in the scale of $5-10 \%$ for low flow rates and ranges to a maximum of $33 \%$ for high flow rates.

\subsection{Size mapping}

The dimensions of ten rising bubbles imaged on 70 frames were determined manually as well as using the automated 

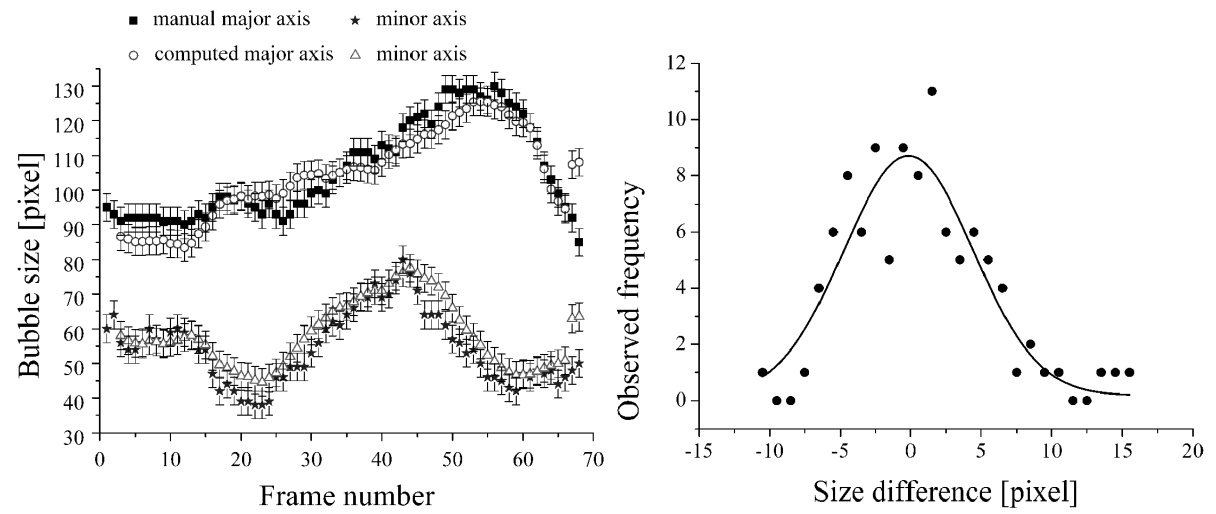

Fig. 3. Left; Comparison between manually measured and computed bubble sizes. The computed major axis (circle line) and the computed minor axis (triangle line) correspond mostly within the error of \pm 4 px with their manually measured counterparts. Right; The frequency distribution for size differences between manually measured and computed axes lengths can be approximated using a Gaussian fit. The error bars are consistent with the standard deviation of $\sigma=4,6 \pm 0,6 \mathrm{px}$.

approach. The bubbles were elliptically shaped. The diameter of their major axis ranged between 1 to $20 \mathrm{~mm}$ (10 to 200 pixels). Figure 3 (left) illustrates the size evolution of one representative bubble. The bubbles oscillating during ascend produce a size variation of both axes. Within the uncertainty of measurement, there is generally a good correspondence between the values based on the automated estimation and those that were determined manually. In the case of the manual size measurement, the uncertainty of $\pm 4 \mathrm{px}$ comprises of $\pm 2 p x$ for the edge determination and $\pm 2 p x$ for estimating the major and minor axis orientation respectively. In the case of the automated measurement the uncertainty of $\pm 4 \mathrm{px}$ constitutes of $\pm 2 \mathrm{px}$ for detecting the blurred edge of the bubble boundary. An additional uncertainty of $\pm 2 \mathrm{px}$ takes possible edge enhancement due to the edge detection process into account. Quantifying the accuracy between manually and automatically measured bubble sizes yields a frequency distribution which is shown in Fig. 3 (right). The difference in bubble size determination is small with a median of $\bar{X}=-0,15 \mathrm{px}$. The standard deviation of $\sigma=4,6 \pm 0,6 \mathrm{px}$ is consistent with the measurement uncertainty illustrated as error bars in Fig. 3 (top).

\subsection{Bubble assignment}

A strategy has been developed assessing how successful bubbles have been tracked by the automated image analyses. Using the least distance assumption, it was manually verified that individual bubbles can be tracked in successive frames. In a second step, the parameter $\beta$ was introduced to quantify the rate of successful assignments for approximately $10^{6}$ bubbles.

In the initial experiment, 23 single bubbles were tracked at a flow rate of $1 \mathrm{~L} / \mathrm{min}$ and their sizes were analysed. The gas flux was created using a pump for aquarium purposes and led into a bare hose. The gas flux was calibrated by mea- suring the time required to fill a volume of $250 \mathrm{ml}$. The orifice was $3 \mathrm{~mm}$ in diameter. It was aligned horizontally in the setup and produced bubbles with irregularly shaped and oscillating bubble surfaces. The major axis diameters varied between approximately $7-12 \mathrm{~mm}$ (70-120 pixels). The bubbles did not overlap and maintained a distance of 6-12 $\mathrm{mm}$ (60-120 pixels) to their predecessors. The automated assignment method resulted in 1150 size measurements. However, the algorithm failed twice to successfully track the individual bubble in successive frames. While there is a gradual change in the sizes of the axis between successive frames (see for example Fig. 3 left), assignment errors appeared as a simultaneous and unsteady break in the measurement of both bubble axes. This indicates that a different bubble of different major and minor axis size had been erroneously tracked. The mistaken assignment can be explained by shape oscillation. In rare cases, sporadic shape deformation can cause a negative rise of the centre of the bubble area. This negative rise excludes the bubble from assignment momentarily.

Based on this information, a strategy was developed in order to investigate the automated bubble assignment method for increased flux and bubble population densities. This was necessary because it is impractical to manually test the analyses capability for large datasets. The strategy is based on two assumptions: It is assumed that the assignment rate can be evaluated by the ratio of the number of assigned bubbles with respect to the total number of bubbles. Furthermore, the gradient of variation in diameter of individual bubble is an indicator for successful individual bubble assignment. The second assumption relates to the observed bubble shape oscillation. Those bubbles which changed in diameter by less than $30 \%$ between successive frames were defined as correctly assigned. The ratio $\beta$ represents the number of assigned bubbles with a differential diameter of less than $30 \%$ with respect to the total number of bubbles observed. 


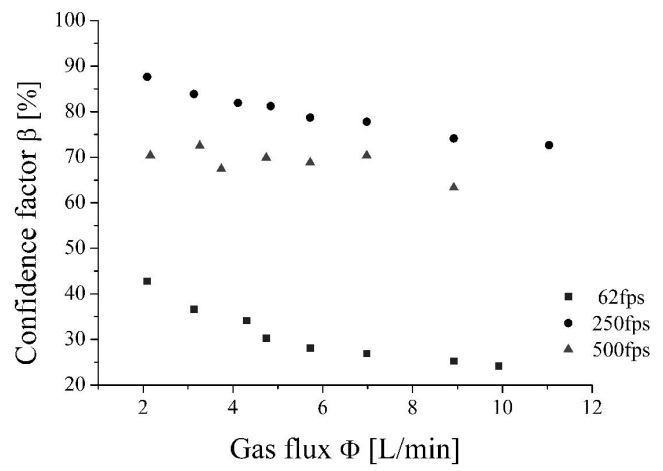

Fig. 4. The ratio $\beta$ shows the flux dependent accuracy of bubble assignment with an assignment of $85 \%$ decreasing to $75 \%$ for $250 \mathrm{fps}$. At $500 \mathrm{fps} \beta$ remains approximately constant for all flow rates while for $62 \mathrm{fps}$ most of the bubbles cannot be assigned successfully.

In a next step, the sensitivity of the assignment procedure was tested for a range of gas flow rates that may be encountered in the natural system. Additionally, the speed of image acquisition varied between 62, 250, and $500 \mathrm{fps}$ to investigate its influence on bubble assignment ability. A hole was drilled into a block of plastic and connected to a pressure vessel. Its orifice was $1 \mathrm{~mm}$ in diameter pointing vertically upwards. An experiment with calibrated flow rates ranging between $2 \mathrm{~L} / \mathrm{min}$ and $12 \mathrm{~L} / \mathrm{min}$ was set up and the parameters were intentionally set to represent a worst-case scenario. This caused rising bubbles to overlap, coalesce and break up again. The flux was determined using a flow meter (Fischer \& Porter; Model NR FP 1/4-20 G5) and controlled by measuring the time that was required to fill a volume of $2 \mathrm{~L}$. Each flow rate was recorded with $500 \mathrm{fps}, 250 \mathrm{fps}$ and $62 \mathrm{fps}$. In each sequence, the total object numbers ranging from $10^{5}$ for $2 \mathrm{~L} / \mathrm{min}$ up to $10^{7}$ for $12 \mathrm{~L} / \mathrm{min}$ were recorded.

Figure 4 shows $\beta$ against gas flux $\Phi$ for three different recording frequencies. The figure illustrates the highest assignment factor was achieved at recording frequencies of $250 \mathrm{fps}$. Neither higher nor lower acquisition frequencies increase the assignment factor. At $62 \mathrm{fps}$ the number of successful assignments is below $45 \%$ at low flux rates and decrease further with increasing flux. This poor assignment ability can be explained by the fact that the least distance assumption is not valid anymore. The distance bubbles travel in between successive frames is larger than the distance of neighbouring bubbles. This is even more obvious at high flow rates which results in high bubble population densities. At $500 \mathrm{fps}$ the assignment factor remains approximately constant for all flow rates with a value of about $70 \%$. At these high acquisition frequencies, the observed bubbles move in average between 2 pixel and 6 pixel per frame. Therefore, the least distance assumption remains valid. In addition, the bubble shape remains nearly identical. However, bubbles that do not rise at all in successive frames are excluded from the assignment in order to prevent misinterpretation of for- eign objects. At acquisition frequencies of $250 \mathrm{fps}$, the ratio decreases steadily from approximately $85 \%$ for $2 \mathrm{~L} / \mathrm{min}$ to $75 \%$ at $12 \mathrm{~L} / \mathrm{min}$. This trend might be explained by the fact that with increasing fluxes the numbers of bubble in each frame increases and that, consequently, more bubbles overlap, which leads to decreasing $\beta$ values. This statement is supported by the observation made in the previous experiment with single bubbles at $1 \mathrm{~L} / \mathrm{min}$. Out of 1150 assignments only two were corrupted yielding a ratio of $\beta=99.8 \%$. In conclusion, $250 \mathrm{fps}$ has been found to be the optimum recording frequency with an assignment factor in the range of $85 \%$ to $75 \%$.

\subsection{Flux measurement}

Lab experiments were conducted in order to test how good the Bubblemeter and the subsequent automated analyses actually measure the bubble flux. The result of the automated analyses shows a linear dependency between the measured and the actual bubble flux. This implies that the calculation routine systematically overestimates the actual flux by a constant factor. It can be shown that the overestimation is caused by irregular bubble shapes which are predominately the result of a two dimensional image projection of the observed volume.

A laboratory experiment was set up to record gas flows and to compute the image data obtained. A water tank $1 \mathrm{~m} \times 1.5 \mathrm{~m} \times 1 \mathrm{~m}$ in dimension was filled with tap water at room temperature $\left(T=20^{\circ} \mathrm{C}\right)$. Three upward pointing nozzles with $5 \mathrm{~mm}, 3 \mathrm{~mm}$ and $1 \mathrm{~mm}$ in diameter were placed $0.7 \mathrm{~m}$ below surface. The Bubblemeter was submerged just underneath the surface. The image size obtained was $30 \mathrm{~cm}$ with the screen at the top $5 \mathrm{~cm}$ below surface. The plume rose in the centre of the observation volume and was completely imaged. The mean distance between plume and camera was $0.8 \mathrm{~m}$ yielding a resolution of $319 \pm 17 \mu \mathrm{m} / \mathrm{px}$. The recording frequencies were set to $500 \mathrm{fps}$ and $250 \mathrm{fps}$. Each sequence contained 1000 frames and recorded a time interval of $2 \mathrm{~s}$ and $4 \mathrm{~s}$ respectively. High pressure Scuba tanks provided the gas supply via low pressure hoses. The gas pressure was reduced to constant intermediate pressure while a fine control valve was used to adjust the appropriate gas flow. The flow rate was monitored using a calibrated flow meter tube (Fischer \& Porter; Model NR FP 1/4-20 G5). Eight measurements in the flow range between $2 \mathrm{~L} / \mathrm{min}$ and $12 \mathrm{~L} / \mathrm{min}$ were taken for each diameter and each of the recording frequencies. All measurements were in the flow regime of bubbly jet streams. Shortly after detachment, every second bubble accelerated within the wake of their predecessors and penetrated them. During the ascent, bubbles broke up and occasionally formed agglomerates again. The observed shapes can be classified as small spherical bubbles, bigger ellipsoids to even larger spherical cap-shaped bubbles.

In order to calculate bubble volumes based on the measured bubble sizes, various models may be used. One model 

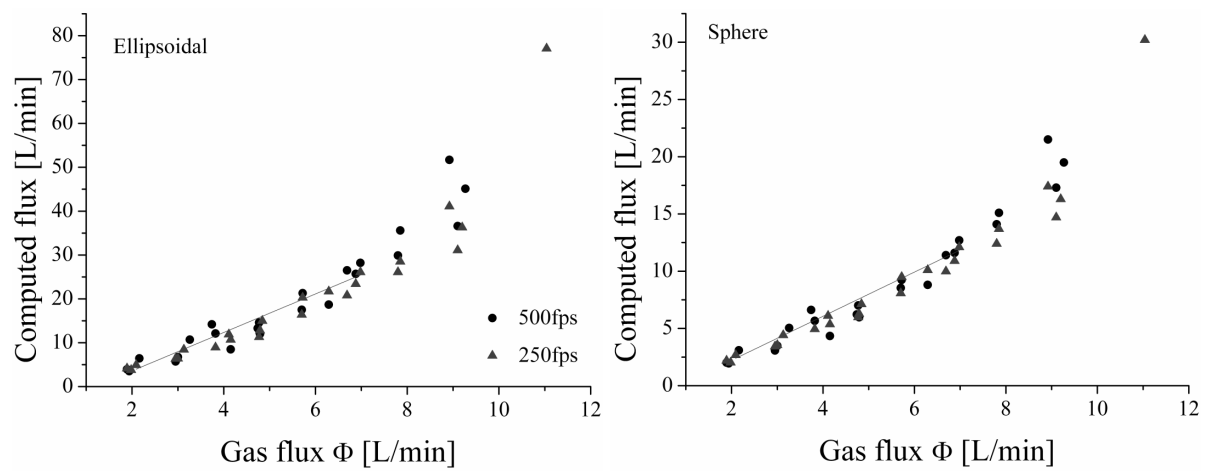

Fig. 5. In both models the computed flux can be linearly correlated to the physical flux. The ellipsoidal model yields an overestimation factor of $4.8 \pm 0.6$ while the sphere model yields an overestimation of $2.2 \pm 0.3$.

Table 1. The frequency combined mean slope for the ellipsoidal model yields a systematic overestimation of $4.8 \pm 0.6$ while the sphere yields $2.2 \pm 0.3$.

\begin{tabular}{lclc}
\hline Model & Frequency (fps) & $B$ & $R^{2}$ \\
\hline \multirow{2}{*}{ Ellipsoidal } & 250 & 4.2 & 0.98850 \\
& 500 & 5.4 & 0.95219 \\
Sphere & 250 & 1.9 & 0.90465 \\
& 500 & 2.4 & 0.99105 \\
\hline
\end{tabular}

assumes an ellipsoidal shape using the bubble length and width as major and minor axis while the bubble depth is assumed to be identical to its width. Another model uses an equivalent area approach: the sphere radius is determined by a circular area which is equivalent to the cross-section area of the particular bubble. For simplicity, this model will be referred to as the sphere model in the following. Both approaches have been applied in order to compare model pending discrepancies but they have been found to be equally valid, as shown further below.

Figure 5 shows a linear correlation between actual and estimated flux resolved for each frequency and model. Table 1 presents the essential linear least square fit parameters for both models and for $500 \mathrm{fps}$ and $250 \mathrm{fps}$, respectively. Within an error of 33\% each model shows a frequency independent linear correlation between estimated and actual flux.

\subsection{Model evaluation}

Both models show a systematic overestimation of the measured gas flux. In order to investigate the origin of the overestimation, the volume of single bubbles and bubble clusters have been estimated manually. The deviation of 4.8 for the ellipsoidal model and 2.2 for the sphere model could be reproduced indicating the source of error to be model induced. In addition, the impact of large bubble clusters to the total

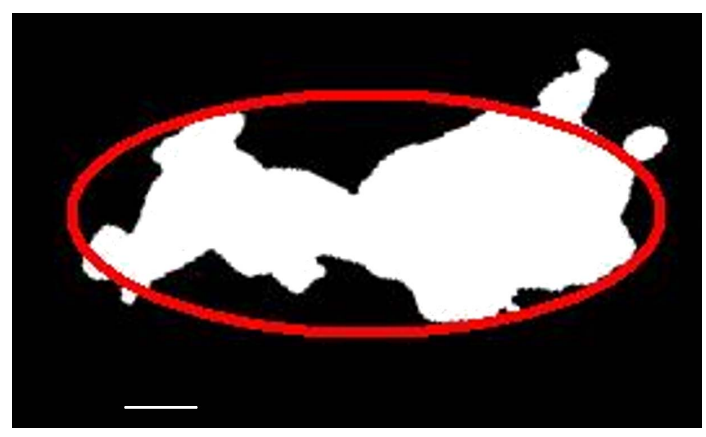

Fig. 6. The compositions of various bubbles merging and overlapping each other create bubble clusters. The volume of a best fit ellipse is larger than the actual gas volume. These clusters carry the majority of gas dominating the overestimated computed flux. The white scale bar below is $1 \mathrm{~cm}$ long.

gas volume was examined. The volume shows a strong dependency on theses clusters emphasizing the model induced overestimation.

The volumes of ten single bubbles oscillating moderately have been compared with the automatically estimated volumes using the ellipsoidal as well as the sphere approach. The ratio of the estimated versus actual volume is denoted as $r_{1}$ for the ellipsoidal and $r_{2}$ for the sphere model. The result is $r_{1}=1.6$ with standard deviation of $\sigma_{1}=0.04$ for the ellipsoidal ratio and $r_{2}=1.3$ with $\sigma_{2}=0.09$ for the sphere ratio. This can be interpreted as a systematic volume overestimation of 1.6 and 1.3, respectively. The same technique was applied to bubble clusters. Artificial bubble clusters are created when the bubble population within the volume of observation is projected onto a two-dimensional image. These artificial bubbles are irregularly shaped and have concave curvatures. Figure 6 shows a cluster example encircled by the best fit ellipse. The result is an overestimation of $r_{1}=3.8$ with $\sigma_{1}=1.4$ for the ellipsoidal and $r_{2}=1.6$ with $\sigma_{2}=0.9$ for the sphere model. This is in good agreement with the observation made earlier where the linear least square fit parameter returned slope values in the same range (Table 1). 

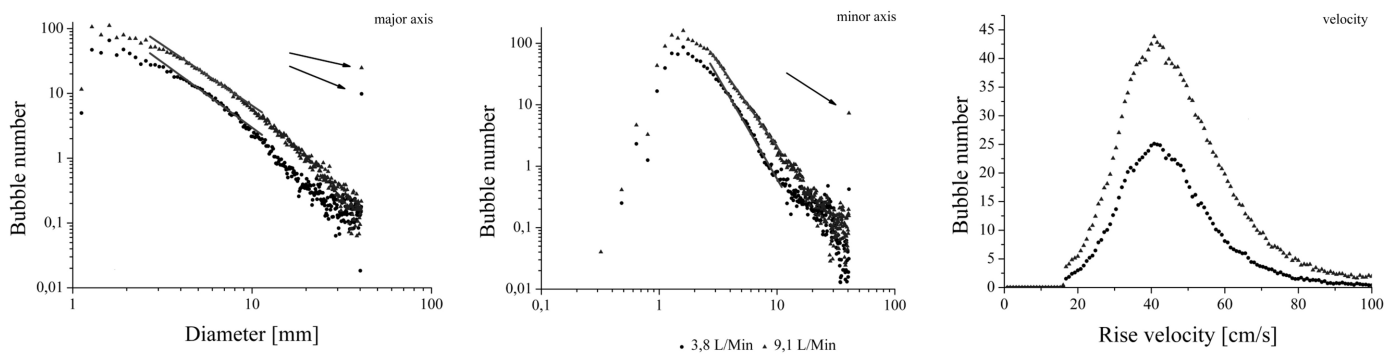

Fig. 7. Bubble size distributions for the major axis (left) minor axis (centre) and rise velocity distribution (right) for $3.8 \mathrm{~L} / \mathrm{min}$ and $9.1 \mathrm{~L} / \mathrm{min}$. An increased gas flux yields increasing bubble numbers while the bubble size and rise velocity distribution remains constant. Note the single peaks at the cut off end of the distribution. These represent large bubble clusters. They are not well approximated by the model and are predominantly responsible for flux overestimation.

Table 2. The gradients for the high and low flow distribution can be approximated using similarly valued parameters. This holds for the major axis as well as for the minor axis distribution in Fig. 7.

\begin{tabular}{lccrc}
\hline Axis & Flux (L/Min) & $\alpha$ & $\gamma$ & $R^{2}$ \\
\hline \multirow{2}{*}{ major } & 3.8 & 2.5 & -2 & 0.98107 \\
& 9.1 & 2.7 & -1.9 & 0.99095 \\
\multirow{2}{*}{ minor } & 3.8 & 3.1 & -3.3 & 0.99182 \\
& 9.1 & 3.0 & -2.7 & 0.99618 \\
\hline
\end{tabular}

\subsection{Volume distribution}

The apparent difference between the ellipsoidal and the sphere model is most pronounced for large irregular shaped bubbles as well as for bubble clusters. Due to lack of rotational symmetry and information on the third dimension, the assumption that bubble width equals bubble depth is not readily valid for large bubbles and clusters. However, these large bubbles and clusters are predominantly responsible for the volume overestimation during automated flux analyses. The peak values at the cut-off end of the size distribution in Fig. 7 indicate that large bubbles and clusters represent a small minority in the size spectrum only. Yet, the automated flux estimation is influenced considerably by the model pending overestimation suggesting only few mega bubbles carry a significant amount of volume.

In order to determine the impact of bubble clusters on the total volume, the size information in the class with the largest sizes (Fig. 7) was extracted. The ratios between bubble volumes in this large-size class with respect to the total gas volume indicate the volume impact of bubble clusters. The results show that less than $1 \%$ to $3 \%$ of all bubbles carry between $30 \%$ and $90 \%$ of the total gas volume. Consequently, due to the limited approximation of artificial bubble clusters their systematic volume overestimation transfers onto the total gas volume computation. This also implies that the models used to estimate the volume are valid for $97 \%-99 \%$ of the observed bubbles. This is an important result and confirms the accuracy of the computed size distribution spectra.

\subsection{Frequency distributions}

Bubble size and rise velocity are two important parameters for mass transfer in gas-liquid two-phase flows such as bubble plumes. Gas exchange is dominated by the interfacial bubble area as well as by the time the surface is exposed to the liquid phase. It is, therefore, essential to test the system capability to determine these parameters within the specified accuracy. For example, Fig. 7 shows the major and minor axis frequency distribution as well as the rise velocity frequency distribution at flow rates of $3.8 \mathrm{~L} / \mathrm{min}$ and $9.1 \mathrm{~L} / \mathrm{min}$, respectively. The orifice diameter was $5 \mathrm{~mm}$ and the acquisition frequency $250 \mathrm{fps}$. The size distribution can be expressed in a power function where $\mathrm{Nb}$ is the bubble number, $\alpha$ is a general constant and $\gamma$ a negative power constant.

$\mathrm{Nb}=\alpha \cdot \mathrm{D}^{\gamma}$

Using the $\log$ representation and the rule $\log \left(10^{\alpha} \times \mathrm{D}^{\gamma}\right)=$ $\alpha+\gamma \times \log \mathrm{D}$, Eq. (2) enables us to determine the power constant by means of the slope of a linear least square fit of the distribution.

Table 2 shows the linear least square fit parameters for the bubble size distributions shown in Fig. 7 (left) and Fig. 7 (centre). For each axis, the size distribution for high and low flow can be approximated by similar linear functions. Consequently, the size distribution does not change for bubbles in between the two measured flow regimes. An increased flow primarily causes increased bubble numbers for the selected flow rates.

The same observation can be made for the velocity distribution in Fig. 7 (right). The data are displayed in a linear scale representation. An increased flux causes increased bubble numbers instead of an increased rise velocity. The mean velocity for $3.8 \mathrm{~L} / \mathrm{min}$ is given by $v=42.3 \pm 0.2 \mathrm{~cm} / \mathrm{s}$ and $\sigma=22.1 \mathrm{~cm} / \mathrm{s}$ while for the flow rate of $9.1 \mathrm{~L} / \mathrm{min}$ the numbers are $v=43.4 \pm 0.2 \mathrm{~cm} / \mathrm{s}$ and $\sigma=24.5 \mathrm{~cm} / \mathrm{s}$. It is noteworthy that for the majority of observed bubbles no significant increased upwelling effect is observed. This unexpected result was further investigated. The individual rise velocity for bubbles with diameters $1.7 \mathrm{~mm}, 2.7 \mathrm{~mm}$ and $3.5 \mathrm{~mm}$ were 
Table 3. For each bubble diameter the terminal velocities by Haberman \& Morton ${ }^{2}$ is added to the fluid velocity determined by Whalley $\&$ Davidson ${ }^{1}$ and compared with the measured values.

\begin{tabular}{lcccc}
\hline $\begin{array}{l}\text { Bubble size } \\
(\mathrm{mm})\end{array}$ & $\begin{array}{c}\text { Bulk flow } \\
(\mathrm{cm} / \mathrm{s})\end{array}$ & $\begin{array}{c}\text { Terminal velocity } \\
(\mathrm{cm} / \mathrm{s})\end{array}$ & $\begin{array}{c}\text { Cumulative velocity } \\
(\mathrm{cm} / \mathrm{s})\end{array}$ & $\begin{array}{c}\text { Measured rise velocity } \\
(\mathrm{cm} / \mathrm{s})\end{array}$ \\
\hline 1.7 & 22 & 19 & 41 & 40.7 \\
2.7 & & 22 & 44 & 44.6 \\
3.5 & & 24 & 46 & 42.7 \\
1.7 & 30 & 19 & 49 & 42.2 \\
2.7 & & 22 & 52 & 45.0 \\
3.5 & & 24 & 54 & 43.0 \\
\hline
\end{tabular}

compared for $3.8 \mathrm{~L} / \mathrm{min}$ and $9.1 \mathrm{~L} / \mathrm{min}$. The bubble sizes were chosen for their local maxima in a two dimensional representation of the size distribution. The result is only a slight increase in rise velocity, varying from $1.5 \pm 0.2 \mathrm{~cm} / \mathrm{s}$ for $1.7 \mathrm{~mm}, 0.4 \pm 0.2 \mathrm{~cm} / \mathrm{s}$ for $2.7 \mathrm{~mm}$ and $0.3 \pm 0.2 \mathrm{~cm} / \mathrm{s}$ for $3.5 \mathrm{~mm}$. These data support the observation made earlier. The bulk flow velocity does not increase with the same rate as the gas flux increases.

A simple approach to this problem is a two-phase model with a non-interacting gas and liquid phase. Here, the gas bubbles rise within a bulk fluid driven by gravity only. The terminal velocity is described as the rise velocity of single bubbles in absence of bulk flow. The potential energy released by the bubble during ascent is converted to kinetic energy of the bulk fluid. The fluid velocity is superimposed by the terminal velocity yielding a total vertical bubble velocity. For simplicity, the total vertical bubble velocity has been referred to as bubble rise velocity in this work. Haberman and Morton investigated the terminal velocity for air in tap water (Haberman and Morton, 1953). They measured terminal velocities between $19 \mathrm{~cm} / \mathrm{s}$ and $24 \mathrm{~cm} / \mathrm{s}$ for the specified bubble diameters. Figure 8 shows the measured rise velocities for each diameter together with the terminal velocity measured by Haberman and Morton. The difference between bubble rise velocity and terminal velocity may be assigned to the upwelling effect of the gas flux causing bulk flow.

The concept of a superficial gas velocity is used in order to quantify the impact of the gas flux to the bulk fluid momentum. The gas velocity is the speed of the gas-liquid interface displacing the fluid within a pipe. For a cross-section area of approximately $A_{\text {cross }}=500 \mathrm{~cm}^{2}$ this yields a gas velocity of $v_{g}=0.13 \mathrm{~mm} / \mathrm{s}$ and $v_{g}=0.3 \mathrm{~mm} / \mathrm{s}$ for $3.8 \mathrm{~L} / \mathrm{min}$ and $9.1 \mathrm{~L} / \mathrm{min}$, respectively. Whalley and Davidson investigated the correlation between bulk fluid velocity $v_{f l}$ and gas velocity $v_{g}$ which causes the bulk flow (Whalley and Davidson, 1977). The results yielded that fluid motions varied between $v_{f l}=22 \mathrm{~cm} / \mathrm{s}$ for $v_{g}=0.1 \mathrm{~mm} / \mathrm{s}$ and $v_{f l}=30 \mathrm{~cm} / \mathrm{s}$ for $v_{g}=0.3 \mathrm{~mm} / \mathrm{s}$. The measurements were carried out in tanks where the height to width ratio was smaller than one and where wall effects could be neglected. Conclusively, the

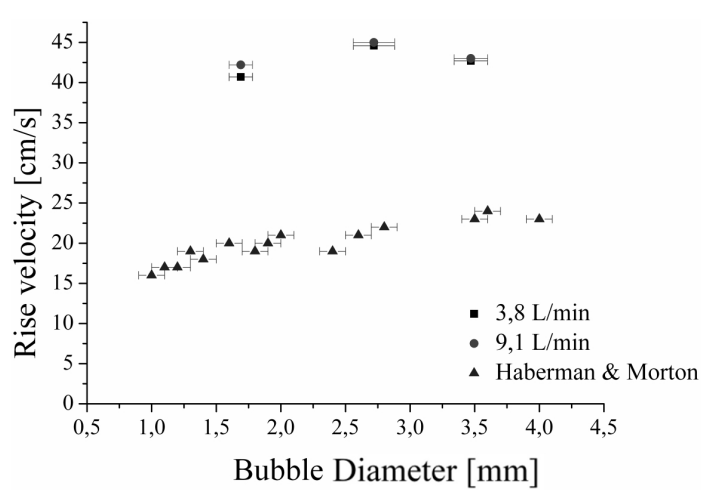

Fig. 8. The measured rise velocities for bubbles with major axis diameters of $1.7 \mathrm{~mm}, 2.7 \mathrm{~mm}$ and $3.5 \mathrm{~mm}$ are plotted for each flow rate. The rise velocity error is given by $2 \mathrm{~mm} / \mathrm{s}$ and equals the size of the plotted objects. Additionally, the terminal velocity measured by Haberman and Morton is shown. The difference between bubble rise velocity and terminal velocity may indicate liquid bulk flow.

measured rise velocities of $v=42.3 \mathrm{~cm} / \mathrm{s}$ and $v=43.4 \mathrm{~cm} / \mathrm{s}$ are in good agreement with the combined results of Whalley \& Davidson and Haberman \& Morton which are displayed in Table 3.

The measurement technique may be verified additionally by further investigating the rise velocity data in Fig. 8. For both gas flux rates, the rise velocity for bubbles with major axis diameters of $3.5 \mathrm{~mm}$ is slightly smaller than for the $2.7 \mathrm{~mm}$ bubbles. The decrease in rise velocity can be explained by the fact that in this size range bubble shapes become flat towards direction of ascend. Thus the ellipsoidal bubble appears more oblate in its surface shape. This effect is frequently observed for bubbly swarms in the absence of surface active substances and causes increased drag, micro turbulences and decreased rise velocities. At the Institute for Environmental Sciences, University of Bremen, a decrease in rise velocity has also been observed for filtered and plain tap water (Schlüter, 2002). He justified these findings with a demonstrable high water quality and low mineral content. Likewise, the water used for the Bubblemeter test originated 
from the same water source and, therefore, showed the same effects.

Another point of interest is the increase of bubble rise velocity for different flux rates. Figure 7, Fig. 8 and Table 3 indicate, that the rise velocity increases between $42.3 \mathrm{~cm} / \mathrm{s}$ and $45.0 \mathrm{~cm} / \mathrm{s}$ opposed to the theoretically anticipated values of $49 \mathrm{~cm} / \mathrm{s}$ and $54 \mathrm{~cm} / \mathrm{s}$. Therefore, a new approach is needed since measuring errors can be excluded as shown above. Instead of dealing with two phases separately, the new approach must consider the interaction of the liquid with the gaseous phase. The observed assumingly reduced rise velocity may be explained by including turbulences, shear stress, momentum transfer and energy dissipation (Brauer, 1979). For low gas contents small bubbles up to approximately $1.5 \mathrm{~mm}$ in diameter rise rectilinear. Above $2.0 \mathrm{~mm}$ bubbles tend to rise on helical pathways. However a further increased gas contents causes bubbles to rise increasingly rectilinear again. (Miyahara and Yamanaka, 1993). As the horizontal velocity component decreases, the vertical component increases. This effect is more pronounced for small bubble diameters and it decreases for larger bubbles. Therefore, bubbles in bubbly swarms or jet streams rise faster than single bubbles measured by Haberman \& Morton. The tendency towards rectilinear bubble motion is influenced by an increasing turbulent flow field around the bubbles.

These instantaneous fluctuations cause bubble deformations which themselves react to the perturbation by producing chaotic and highly variable flow fields organized as eddies (Serizawa et al., 1975; Schlüter, 2002). With increasing gas contents, the bubble-induced turbulences become more dominant resulting in an increased flow resistance. Eddies also increase the exchange of momentum between the bulk fluid and its boundary, causing a reduced velocity gradient profile (Brauer, 1971 and 1979).

Thus, the barely increasing observed bubble rise velocity in Table 4 can be explained by an eddy induced increased flow resistance together with a decreasing velocity gradient profile in the bulk fluid.

\subsection{Error estimation and impact}

The error for gas flux determination is a combination of optical resolution, bubble segmentation, assignment ability and model accuracy. Optical resolution and bubble segmentation errors remain constant for all flow rates. The assignment ability and the model accuracy, however, vary with the flux related bubble population density. The latter two dominate the absolute error significantly. In order to discuss the error estimation, the end members in the bubble-size spectrum may be distinguished and discussed separately.

Most numerous were those bubbles with a small bubble size of about $3 \mathrm{~mm}$ (ca. $10 \mathrm{px}$ ) in diameter. For this case, the optical uncertainty of $\sigma=17 \mu \mathrm{m} / \mathrm{px}$ causes a volume error of $16 \%$. The segmentation error of \pm 4 px contributes with up to $100 \%$. Because small bubbles can be considered spheri-

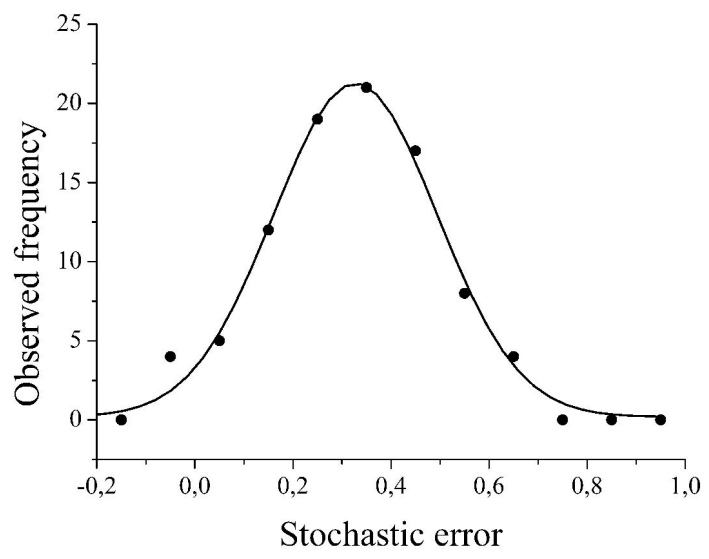

Fig. 9. The frequency distribution for the relative variance between measured and computed flux is illustrated. Using a Gaussian fit the stochastic error of the computed flux can be approximated. The median error of $33 \%$ corresponds to the evaluated theoretical error of $34 \%$.

cally shaped, the model error is negligible. The error caused by unsuccessful bubble assignment can only be estimated. As mentioned above, an unsuccessful assignment excludes the bubble volume momentarily from computation. An upper error limit is given by $100 \%-\beta$ indicating the proportion of unsuccessful assignments. Most of the failed assignments will concern small bubbles. Therefore, it is assumed that the assignment error is in the range of $15 \%-25 \%$ for sequences with an acquisition frequency of $250 \mathrm{fps}$. Summation over all values above yields a maximum error of $141 \%$. For flux determination, this value must be weighted with the relative volume transported through small bubbles which is as low as $10 \%$. This may lead to a minimum flux error of approximately $14 \%$ caused by small bubbles.

Large irregular-shaped bubbles and clusters of bubbles represent a small minority in the size distribution, but these bubbles transport up to $90 \%$ of the total volume. Their size ranged from $40 \mathrm{~mm}(128 \mathrm{px})$ to several centimetres. The optical uncertainty causes an error of $16 \%$. The segmentation error is less sensitive to large bubbles due to the small relative change in bubble diameter. It is below $9 \%$ and decreases steadily for bubbles larger than $40 \mathrm{~mm}$ in diameter. The assignment error is negligible for large bubbles. For these bubbles the distance travelled between successive frames is smaller than the bubble dimensions. Consequently, the centre of area transposes within the boundary of the same bubble. Therefore, no other bubble can interfere with the correct bubble assignment. The model accuracy can be approximated by a linear flux overestimation. This assumption requires detailed knowledge about the bubble size distribution which, however, can be extracted by the same dataset. The error due to an uncertainty in the experimentally determined overestimation factor of 4.8 for the ellipsoidal model can be estimated by dividing its mean deviation of \pm 0.6 with 
respect to the overestimation factor. The same result may be obtained for the sphere model by dividing the deviation of \pm 0.3 with respect to the overestimation factor of 2.2. This results in an error of $13 \%$. Summing over the errors of the second bubble class and weighting with the relative volume yields an error of approximately $34 \%$. This estimated theoretical value has been verified experimentally.

After correcting the automatically estimated flux data for the systematic overestimation, the relative variance between actual and estimated flux was determined. The cumulative result for $500 \mathrm{fps}$ and $250 \mathrm{fps}$ including both models is illustrated in Fig. 9. The random error $E$ in flux determination can be approximated by a Gaussian fit. The median error is $\bar{E}=0.33$ with a standard deviation of $\sigma=0.31$. These values are in good agreement with the anticipated theoretical error of $34 \%$.

The error in bubble rise velocity may be estimated as follows. For the uncertainty in rise velocity, error propagation may be applied. The centre of the bubble area may be determined within the limit of 0.5 pixel. This value is justified by the continuous Gaussian shape distribution in Fig. 7. The result of multiplying this value with the differential resolution yields a rise velocity uncertainty of $2.1 \mathrm{~mm} / \mathrm{s}$.

\section{Discussion}

The objective of the work presented is to introduce a new design for gas quantification under water. One key element of the system is the image analysis routine. It could be shown that bubbles are isometrically mapped onto binary images. Test procedures were introduced proving the system's ability of successfully tracking bubbles within the volume of observation and to quantify the rate of successful bubble assignments. Laboratory measurements indicate a linear dependency between estimated and actual gas flux. A systematic overestimation of $4.8 \pm 0.6$ was calculated for the gas flux using an ellipsoidal model. For the sphere model, the overestimation was $2.2 \pm 0.3$. The initial objective has been met under laboratory condition. The optical system is capable of quantifying gas flow rates in the range between $2 \mathrm{~L} / \mathrm{min}$ and $10 \mathrm{~L} / \mathrm{min}$ with an uncertainty of $33 \%$. The verification process has identified limitations of the new gas quantification system.

\subsection{Limiting parameters}

The performance depends on three primary parameters, such as acquisition frequency, image size as well as bubble population density. Other parameters such as bubble size, rise velocity, bubble shape and sequence length can be derived from those mentioned above.

Acquisition frequency: Frequencies which are too high cause bubble exclusion due to momentarily nil or negative rise velocities. On the other hand, frequencies that are too low, i.e. $62 \mathrm{fps}$ inhibit successful bubble tracking. Therefore, an upper limit of $500 \mathrm{fps}$ for analysing bubble plumes can be set. For the low frequency side, the bubble population density must be taken into account. The higher the population density, the shorter the mean distance between the nearest neighbours. Consequently, the higher the acquisition frequency must be. At flow rates between $2 \mathrm{~L} / \mathrm{min}$ and $10 \mathrm{~L} / \mathrm{min}$ $250 \mathrm{fps}$ was identified as ideal recording speed.

Image size: The minimum vertical image size has been found to be $150 \mathrm{px}$. This is approximately three times the size of the vertical dimension of the largest bubbles observed. Increasing the image size from $150 \mathrm{px}$ to $500 \mathrm{px}$ improved the number of successful bubble assignments steadily. Above $500 \mathrm{px}$ the rate of successful assignment remained constant. It is, therefore, suggested that for further applications, the dimension of vertical image size is ten times the height of the largest observed bubble, in this case $500 \mathrm{px}$.

Bubble population density: Unlike frequency and image size, this natural parameter can not be controlled in deepsea applications. Essentially it affects bubble agglomeration and formation of two dimensional projected bubble clusters. Generally, flow rates of $2 \mathrm{~L} / \mathrm{min}$ and above result in bubble populations densities which cause significant bubble agglomeration and formation of bubble clusters on the images. Flux computation is then only possible using predetermined calibration factors.

After having completed stage 1 of the development process, the next step in the assessment process is to verify that the system can be deployed under deep-sea conditions. The Bubblemeter was, therefore, deployed to $1023 \mathrm{~m}$ water depth during the M74/3 research expedition at the Makran accretionary prism in November 2007. During that cruise, the remote operated vehicle (ROV) 'Quest' was launched from the research vessel R/V Meteor in order to investigate active gas seeps offshore Pakistan. The Bubblemeter was mounted onto the front porch of the ROV. The camera was operated in the built-in autonomous mode and synchronised with the illumination device. The Bubblemeter was positioned at an active bubble stream (Fig. 10, left). The camera and light were turned on using the ROV manipulator. A two-second sequence with 1000 single images was recorded at a frequency of 500 frames per second. Figure 10 (right) shows one image taken by the high-speed camera. The in situ flux was determined to be $140 \pm 10 \mathrm{~mL} / \mathrm{min}$. Due to a small bubble population density and well-approximated bubble shapes, the error was primarily caused by optical resolution uncertainty.

\section{Comments and recommendations}

Unpublished observations at bubble streams indicate that the gas flux at deep-sea bubble ebullition sites can vary according to the tidal cycle. Therefore, it is the objective to upgrade the Bubblemeter so that it can operate autonomously over a period of several tidal cycles. Video sequences should be 


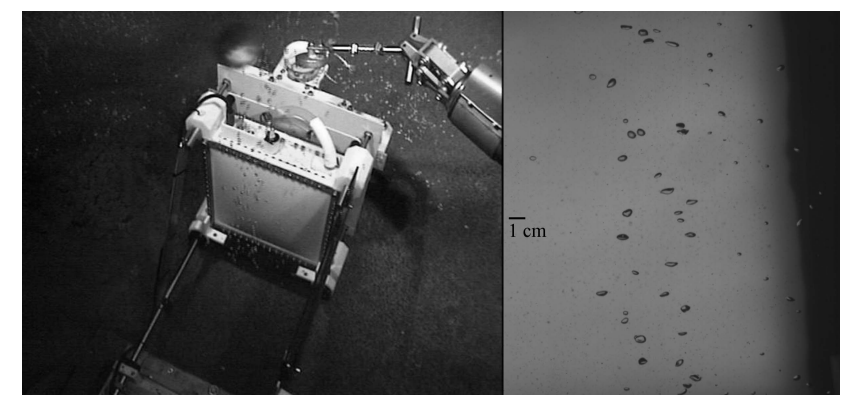

Fig. 10. Left photo taken by the ROV operational camera; CMARUM. The Bubblemeter is positioned and ready to be triggered by the ROV manipulator. Right: Gas bubbles rise in between the camera and the illumination device. The black bar positioned at the centre left is scaled to $1 \mathrm{~cm}$.

taken at intervals of about $2 \mathrm{~h}$ or less in order to obtain sufficient samples within the tides. The system is intended to cycle between a recording, data transfer and stand-by mode. To achieve this goal, three key elements have to be added to the current design.

Camera: The camera specifications have been identified during the test procedures. The camera must record $250 \mathrm{fps}$ at VGA resolution. The camera interface is ideally GENICAM conform and has a GB Ethernet connection. Cameras with these specifications are available on the market and have a power consumption of $5 \mathrm{~W}$.

Control unit: An embedded PC system must be designed to control the camera, the illumination device and to transfer the image data onto a memory device. The unit will reach a power consumption of $30 \mathrm{~W}$ during peak performance. The external memory device will have a capacity of $120 \mathrm{~GB}$ and be able to store about 100 sequences. Limited memory space is the restricting resource of the autonomous device.

Power: During the last deployment, valuable data on power consumption of the utilized $10 \mathrm{Ah} \mathrm{Li-Po} \mathrm{battery} \mathrm{pack}$ has been obtained. Particularly, temperature reduces the nominal power capacity. In the laboratory, the capacity was sufficient for 60 test runs each $10 \mathrm{~s}$ of duration. Power consumption during deep-sea deployment suggests that only 20 cycles would have been possible in situ. Therefore, it is planned using a $40 \mathrm{Ah} \mathrm{Li-Po} \mathrm{battery} \mathrm{pack} \mathrm{and} \mathrm{reducing} \mathrm{the}$ interval to $5 \mathrm{~s}$. Theoretically, this enables 80-160 sequences to be illuminated. The control unit is intended to run independently on a $10 \mathrm{Ah} \mathrm{Li-Po} \mathrm{battery} \mathrm{pack.} \mathrm{This} \mathrm{will} \mathrm{allow} \mathrm{the}$ unit to run a minimum of $1 \mathrm{~h}$ at peak performance in situ.

Improvements on behalf of camera, power- and information storage equipment will lead to a monitoring device with an anticipated performance of 100 sequences in $15 \mathrm{~min}$ intervals over a period of $24 \mathrm{~h}$. Although memory capacity is the limiting factor for the deployment duration, the system will not process the image data in situ. There are two reasons against it. Firstly, any optical misinterpretation such as marine snow or barnacles can not be identified without the raw images. Secondly, raw images may be of great value when examining the bubble-fluid interface within the hydrate stability zone.

Some valid critical aspects of the system setup are its limited field of observation and lack of quantifying flux rates over a large scale seep field. Also the device must be positioned precisely on top of an active seep. The purpose of the present device is local high resolution imaging of single gas vents. Large scale quantification may be achieved using additional acoustical backscattering methods for example.

Acknowledgements. We would like to thank Ira Leifer and Aneta Nikolovska for their expertise during numerous helpful discussions. We also thank and appreciate the constructive comments made by the reviewers and the guest editor. Special thanks go to Wilfried Schütz and Uwe Grossmann for their continuous encouragement. We would like to thank the crew of the research vessel $\mathrm{R} / \mathrm{V}$ Meteor as well as the ROV operators whose great efforts turned the "Bubblemeter" deployment into a success.

This research was part of "MarTech" and primarily funded by the Helmholtz Association as part of the "Impuls- und Vernetzungsfonds". Furthermore, the study was partly funded by the DFG-Research Center/Excellence Cluster "The Ocean in the Earth System". The project received further helpful support by the Institute for Marine Resources, Bremerhaven, and ERDF (European Regional Development Fund).

Edited by: G. Griffiths

\section{References}

Agrawal, Y. C. and Pottsmith, H. C.: Autonomous Long-Term in situ Particle Sizing Using A New Laser Diffraction Instrument, OCEANS, 5, 1575-1580, 1989.

Belcher, E. O.: Quantification of Bubbles Formed in Animals and Man During Decompression, IEEE Trans. Biomed. Eng. 27, 330-338, 1980.

Brauer, H.: Grundlagen der Einphasen- und Mehrphasenströmungen, Verlag Sauerländer, Aarau und Frankfurt am Main, 1971.

Brauer, H.: Turbulenzen in mehrphasigen Strömungen, Chem.-Ing.Tech., 51, 934-948, 1979.

Boetius, A., Ravenschlag, K., Schubert, C. J., Rickert, D., Widdel, F., Gieseke, A., Amann, R., Jørgensen, B. B., Witte, U., and Pfannkuche, O.: A marine microbial consortium apparently mediating anaerobic oxidation of methane, Nature, 407, 623-626, 2000.

Canny, J.: A Computational Approach to Edge Detection. IEEE Trans., Pattern Analysis and Machine Intelligence, 22, 679-698, 1986.

Deane, G. D. and Stokes, M. D.: Scale dependence of bubble creation mechanisms in breaking waves, Nature, 418, 839-844, 2002.

Deckwer, W.-D.: Reaktionstechnik in Blasensäulen, Otto Salle Verlag, Frankfurt am Main und Verlag Sauerländer, Aarau, 1985. 
de Vries, A. W. G., Biesheuvel, A., and van Wijngaarden, L.: Notes on the path and wake of a gas bubble rising in pure water, Int. J. of Multiphase Flow, 28, 1823-1835, 2002.

Eisma, D., Schuhmacher, T., Boekel, H., van Heerwaarden, J., Franken, H., Laan, M., Vaars, A., Eijgenraam, F., and Kalf, J.: A camera and image-analysis system for in situ observation of flocs in natural waters, Neth. J. Sea Res., 27, 43-56, 1990.

Greinert, J. and Nützel, B.: Hydroacoustic experiments to establish a method for the determination of methane bubble fluxes at cold seeps, Geo. Mar. Lett., 24, 75-85, 2004.

Haberman, W. L. and Morton, R. K.: An experimental investigation of the drag and shape of air bubbles rising in various liquids, Report 802, Navy Dept., David W. Taylor Model Basin, 68 Washington DC, 1953.

Hornafius, J. S., Quigley, D., and Luyendyk, B. P.: The world's most spectacular marine hydrocarbon seeps (Coal Oil Point, Santa Barbara Channel, California): Quantification of emissions, J. Geophys. Res., 104, 20703-20711, 1999.

Judd, A. G.: Natural seabed gas seeps as sources of atmospheric methane, Environ. Geol., 46, 988-996, 2004.

Karpen, V., Thomsen, L., and Suess, E.: A new ,schlieren' technique application for fluid flow visualization at cold seep sites, Mar. Geol., 204, 145-159, 2004.

Lamarre, E. and Melville, W. K.: Instrumentation for the measurement of void-fraction in breakingwaves: Laboratory and field results, IEEE J. Oceanic Eng., 17, 204-215, 1992.

Leighton, T. G., Ramble, D. G., Phelps, A .D., Morfey, C. L., and Harris, P. P.: Acoustic detection of gas bubbles in a pipe, Acta Acustica, 84, 801-814, 1998.

Leifer, I. and Patro, R. K.: The bubble mechanism for methane transport from the shallow sea bed to the surface: A review and sensitivity study, Cont. Shelf Res., 22, 2409-2428, 2002.

Leifer, I., De Leeuw, G., Cohen, L. H., and Kunz, G.: Calibrating optical bubble size by the displaced mass method, Chem. Eng. Sci., 58, 5211-5216, 2003.

Leifer, I. and MacDonald, I.: Dynamics of the gas flux from shallow gas hydrate deposits: interaction between oily hydrate bubbles and the oceanic environment, Earth Planet. Sci. Lett., 210, 411424, 2003.

Leifer, I. and Boles, J.: Measurement of marine hydrocarbon seep flow through fractured rock and unconsolidated sediment, Mar. Pet. Geol., 22, 551-568, 2005.

MacKay, R. S. and Rubisson, J. R.: Decompression studies using ultrasonic imaging of bubbles, IEEE Trans. Biomed. Eng., 25, 537-544, 1978.

McGinnis, D. F., Greinert, J., Artemov, Y., Beaubien, S. E., Wüest, A.: Fate of rising methane bubbles in stratified waters: How much methane reaches the atmosphere?, J. Geophys. Res., 111, CO9007, doi:10.1029/2005JC003183, 2006.

Michelson, D. L., Longe, J. W., Smith, T. A., and Suggs, J. A.: A micro bubble dispersion inwater - what role in industrialwaste treatment? Proceeding of Mid-Atlantic Industrial WasteWater and Hazardous Materials Conference, 13-30, 1988.

Miyahara, T. and Yamanaka, S.: Mechanics of motion and deformation of a single bubble rising through quiescent highly viscous Newtonian and non-Newtonian media, J. of Chem. Eng. Japan, Tokyo 26(3), 297-302, 1993.

Nikolovska, A. and Waldmann, C.: Passive acoustic quantification of underwater gas seepage, OCEANS 2006, 1, 1-6,
doi:10.1109/OCEANS.2006.306926, 2006.

Nikolovska, A., Manasseh, R., and Ooi, A.: On the propagation of acoustic energy in the vicinity of a bubble chain, J. Sound Vib., 306, 507-523, 2007.

Nikolovska, A., Sahling, H., and Bohrmann, G.: Hydroacoustic methodology for detection, localization, and quantification of gas bubbles rising from the seafloor at gas seeps from the eastern Black Sea, Geochem. Geophys. Geosyst., 9, Q10010, doi:10.1029/2008GC002118, 2008.

Orphan, V. J., House, C. H., Hinrichs, K.-U., McKeegan, K. D., and DeLong, E. F.: Methane-consuming archaea revealed by directly coupled isotopic and phylogenetic analysis, Science, 293, 484487, 2001.

Reible, D. D.: Fundamentals of Environmental Engineering, CRC Press, 1999.

Sahling, H., Bohrmann, G., Artemov, Y., Bahr, A., Brüning, M., Klaucke, I., Kozlova, E., Nikolovska, A., Pape, T., and Wallmann, K.: Vodyanitskii Mud volcano, Sorrokin Trough, Black Sea: Geological characterization and quantification of gas bubble streams, Mar. Petrol. Geol., 26(9), 1799-1811, doi:10.1016/j.marpetgeo.2009.01.010, 2009.

Sauter, E. J., Muyakshin, S. I., Charlou, J. L., Schluter, M., Boetius, A., Jerosch, K., Damm, E., Foucher, J.-P., and Klages, M.: Methane discharge from a deep-sea submarine mud volcano into the upper water column by gas hydrate-coated methane bubbles, Earth Planet. Sc. Lett. 243, 354-365, 2006.

Schlüter, M.: Blasenbewegung in praxisrelevanten Zweiphasenströmungen, Fortschr.-Ber. VDI Reihe 7 Nr. 432, Düsseldorf, VDI Verlag, 2002.

Serizawa, A., Kataoka, I., and Michiyoshi, I.: Turbulence structure of air-water bubbly flow, Int. J. Multiphase Flow, 13, 221-259, 1975.

Suess, E., Torres, M. E., Bohrmann, G., Collier, R. W., Rickert, D., Goldfinger, C., Linke, P., Heuser, A., Sahling, H., Heeschen, K., Jung, C., Nakamura, K., Greinert, J., Pfannkuche, O., A. Tréhu, A., Klinkhammer, G., Whiticar, M.J., Eisenhauer, A., Teichert, B., and Elvert, M.: Sea floor methane hydrates at Hydrate Ridge, Cascadia Margin, edited by: Paull, C., Natural gas hydrates: Occurrence, distribution, and detection, Geophysical Monograph 124, American Geophysical Union, 2001.

Stokes, M. D., and Deane, G. B.: A new optical instrument for the study of bubbles at high void fractions within breaking waves, IEEE J. of Oceanic Eng., 24, 300-311, 1999.

Taboada, B., Vega-Alvarado, L., Cordova-Aguilar, M. S., Galindo, E., and Corkidi, G.: Semi-automatic image analysis methodology for the segmentation of bubbles and drops in complex dispersions occurring in bioreactors, Exp. Fluid, 41, 383-392, 2006.

Torres, M. E., McManus, J., Hammond, D., de Angelis, M. A., Heeschen, K., Colbert, S., Tryon, M. D., Brown, K. M., and Suess, E.: Fluid and chemical fluxes in and out of sediments hosting methane hydrate deposits on Hydrate Ridge, OR, I: Hydrological provinces, Earth Planet. Sc. Lett., 201, 525-540, 2002.

Whalley, P. B., and Davidson, J. F.: Proc. Symp on Multiphase Flow Systems, Inst. Chem. Eng. Symp., Series No38, J5, London, 1977.

Zielinski, O., Saworski, B., and Schulz, J.: Marine bubble detection using optical-flow techniques, J. Eur. Opt. Soc.-Rapid, 5, 1-5, doi:10.2971/jeos.2010.10016s, 2010. 